\title{
IDENTIFICACIÓN DE Fusarium EN GRANOS DE FRIJOL NEGRO (Phaseolus vulgaris L.) EN COSTA RICA*
}

\author{
Ana Zulay Guido-Moral, Mónica Blanco-Meneses², \\ María del Milagro Granados-Montero ${ }^{3}$, María Viñas-Meneses ${ }^{4 / * *}$ \\ Palabras clave: Micotoxinas; frijol común; Phaseolus vulgaris; Costa Rica. \\ Keywords: Mycotoxins; common beans; Phaseolus vulgaris; Costa Rica.
}

Recibido: 29/09/2020

Aceptado: 16/12/2020

\section{RESUMEN}

Introducción. El frijol común (Phaseolus vulgaris L.) es una leguminosa consumida ampliamente en países en vías de desarro1lo. En Costa Rica su consumo es alto (10,54 kg.persona ${ }^{-1}$.año $\left.{ }^{-1}\right)$ y su producción se localiza principalmente en regiones al sur y al norte del país. Los granos de esta leguminosa podrían estar contaminados con Fusarium, un hongo micotoxigénico que coloniza diferentes cultivos. Objetivo. Identificar las especies de Fusarium que colonizan los granos de frijol negro en Costa Rica. Materiales y métodos. Se recolectaron 49 muestras de granos de frijol negro durante 2017, 2018 y 2019 en regiones donde se produce este grano en Costa Rica. Estas se utilizaron para aislar e identificar las especies de Fusarium basado en secuencias parciales de los genes TEF$1 \alpha$ (factor de elongación de la traducción 1-alfa) y RPB2 (subunidad de la ARN polimerasa II). Resultados. Se obtuvieron 28 aislamientos de Fusarium, de los cuales $82 \%$ pertenecen al complejo de especies Fusarium incarnatum-equiseti

\footnotetext{
* Esta investigación formó parte de la tesis de licenciatura de la primera autora.

** Autora para correspondencia. Correo electrónico: maría.vinasmeneses@ucr.ac.cr

1 Universidad de Costa Rica, Centro de Investigación en Granos y Semillas (CIGRAS), Costa Rica.

(D) 0000-0002-9810-9631.
}

\begin{tabular}{|c|c|}
\hline \\
\hline \multicolumn{2}{|c|}{$\begin{array}{l}\text { Identification of Fusarium species in } \\
\text { black bean grains (Phaseolus vulgaris L.) from } \\
\text { Costa Rica. Introduction. The common bean } \\
\text { (Phaseolus vulgaris L.) is a legume that is widely } \\
\text { consumed in developing countries. In Costa Rica, } \\
\text { its consumption is still high (10.54 kg.person-1. } \\
\text { year }{ }^{1} \text { ), and its production is mainly located in the } \\
\text { southern and the northern regions of the country. } \\
\text { The grains of this legume could be contaminated } \\
\text { with Fusarium, a mycotoxigenic fungus that } \\
\text { colonizes different crops. Objective. Identify } \\
\text { Fusarium species that colonize the grains of Costa } \\
\text { Rican black beans. Materials and methods. } \\
\text { Forty-nine samples of black bean grains were } \\
\text { collected during } 2017,2018 \text { and } 2019 \text { in different } \\
\text { regions where this grain is produced in Costa } \\
\text { Rica. Those were used to isolate and identify the } \\
\text { Fusarium species based on the partial sequences } \\
\text { of TEF-1 } \alpha \text { (translation elongation factor } 1 \text {-alpha) } \\
\text { and RPB2 genes (RNA polymerase II subunit). } \\
\text { Results. A total of } 28 \text { Fusarium isolates were } \\
\text { obtained, of which } 82 \% \text { belong to the Fusarium }\end{array}$} \\
\hline & \\
\hline & $\begin{array}{l}\text { Universidad de Costa Rica, Centro de Investigación } \\
\text { en Protección de Cultivos (CIPROC), Costa Rica. } \\
\text { (D) 0000-0002-0321-7729. }\end{array}$ \\
\hline & $\begin{array}{l}\text { Universidad de Costa Rica, Centro de Investigación } \\
\text { en Granos y Semillas (CIGRAS), Costa Rica. } \\
\text { (D) 0000-0003-0644-0579. }\end{array}$ \\
\hline
\end{tabular}


(FIESC). La presencia de especies de Fusarium varió según el año de recolección; en el 2018 se encontró la menor prevalencia (43\%) y el 2019 la mayor (76\%). El $71 \%$ de las especies de Fusarium se aislaron de muestras recolectadas en la región sur del país. F. equisetti se aisló solo de una muestra procedente de la región Atlántica, mientras que $F$. incarnatum, $F$. oxysporum y $F$. verticillioides se encontraron distribuidos en muestras colectadas en diferentes regiones del país. Conclusión. El presente estudio demostró la diversidad de especies de Fusarium que colonizan los granos de frijol negro en Costa Rica según la ubicación geográfica y el año de recolección de la muestra. La mayoría de las especies aisladas resultaron productoras de micotoxinas que causan efectos adversos en la salud humana.

\section{INTRODUCCIÓN}

El frijol común (Phaseolus vulgaris L.) es una leguminosa originaria de América; se extiende desde el norte de México, Centroamérica, hasta el noroeste de Argentina (Blair et al. 2010). Actualmente, esta leguminosa, junto con otras 5 especies domesticadas pertenecientes al género Phaseolus, son las más consumidas principalmente en África, Asia y América Latina (FAO 2019). El grano contribuye a la seguridad alimentaria en esas regiones, debido a su alto valor nutricional como fuente de proteínas, minerales, vitaminas y antioxidantes (Broughton et al. 2003, Oomah et al. 2005, Gepts et al. 2008, Blair et al. 2010, Mensack et al. 2010). En Costa Rica, es de alto consumo (10,54 kg.persona ${ }^{-1}$. año1) (FAO 2018) y ocupa el segundo lugar en área cosechada y sembrada después del arroz (SEPSA 2018). La producción de frijol durante el período incarnatum-equiseti species complex (FIESC). The presence of Fusarium species was high and varied according to the year of sample collection; thus 2018 was the year in which the lowest prevalence was found (43\%) and 2019 the highest $(76 \%)$. Seventy-one percent of the Fusarium species were isolated from samples collected in the Brunca region in southern Costa Rica. F. equisetti was isolated only from one sample obtained from the Huetar Atlántica region, while $F$. incarnatum, $F$. oxysporum and $F$. verticillioides were found distributed in samples collected in different regions of the country. Conclusion. The present study demonstrates the diversity of Fusarium species colonizing black bean grains in Costa Rica according to the geographical location and the year of collection of the samples. Most of the isolated species are well known producers of mycotoxins that cause adverse effects on human health.

2018/2019 fue de 9510 toneladas (SEPSA 2019). La mayor producción se obtiene de la Región Brunca (51\%), seguido de la Región Huetar Norte (30\%), mientras que el resto de la producción se localiza en la Región Chorotega (16\%) y otras regiones del país que producen menos del 3\% (SEPSA 2019).

Los hongos que colonizan los granos de frijol afectan su calidad e inocuidad, por lo tanto, su identificación reviste importancia. Algunos de estos hongos son micotoxigénicos, los cuales, bajo condiciones de temperatura y humedad óptimas, pueden producir metabolitos secundarios conocidos como micotoxinas que afectan la salud humana y animal (Perrone et al. 2020). La contaminación de granos y cereales por micotoxinas es de interés mundial, ya que se estima que el $25 \%$ de los productos agrícolas están contaminados con estas toxinas (Eskola et al. 2019) y su ingestión puede causar enfermedades en 
humanos a mediano y largo plazo como cáncer o inmunodeficiencias (Omotayo et al. 2019). Se conocen más de 300 micotoxinas, entre ellas las aflatoxinas, fumonisinas, ocratoxinas, patulina, tricotecenos y zearalenona las de mayor relevancia pues afectan la seguridad alimentaria (Marín et al. 2013, Omotayo et al. 2019).

Fusarium Link es un género de hongos ampliamente distribuido y ha sido identificado como agente causal de enfermedades en diferentes cultivos, así como generador de numerosas micotoxinas (Summerell et al. 2010). Las principales toxinas producidas por Fusarium son fumonisinas, zearalenona y tricotecenos tipo A (HT-2 y toxina T-2) y tipo B (deoxinivalenol y nivalenol) (Munkvold 2017, Jiménez-García et al. 2018). Las especies pertenecientes a este género son saprófitas o patógenas (Singleton y Sainsbury 2006) y la mayoría de ellas producen micotoxinas, principalmente las siguientes: $F$. acuminatum, $F$. langsethiae, $F$. poae, $F$. sambucinum, $F$. sporotrichioides, $F$. venenatum (productoras de tricotecenos tipo A), F. graminearum, $F$. culmorum, $F$. crookwellense, $F$. pseudograminearum, $F$. venenatum (productoras de tricotecenos y zearalenona tipo A), F. proliferatum y $F$. verticillioides (productoras de fumonisinas) (Munkvold 2017). A diferencia de otros hongos, que contaminan los granos durante el secado y almacenamiento, Fusarium puede colonizar y producir toxinas tanto en el campo, en la poscosecha como en el almacén (Antonissen et al. 2014).

La mayor parte de la investigación relacionada con Fusarium y la prevalencia de micotoxinas asociadas a este hongo, se centra en cultivos de alta demanda en todo el mundo, como los cereales (Cinar y Onbaşı 2019). En granos de frijol común, por el contrario, hay poca información. Existen solamente 4 estudios a nivel mundial que reportan la presencia de Fusarium en granos de frijol común (Hitokoto et al. 1981, Abdel-Hafez 1984, Tseng et al. 1995, Castillo et al. 2004); sin embargo, el reporte más reciente es del 2004 y otros estudios, no precisan el tipo de frijol analizado. Por un lado, Castillo et al.
(2004) reportaron resultados de frijol negro producido en Latinoamérica, mientras que en Canadá, Japón y Taiwán reportaron la presencia de diferentes especies de Fusarium en granos de frijol: F. culmorum, F. graminearum, F. oxysporum, F. solani y F. verticillioides (Hitokoto et al. 1981, Tseng et al. 1995). Además, Abdel-Hafez (1984) reportó 3 especies de Fusarium (F. oxysporum, $F$. solani, $F$. verticillioides) en frijoles de Arabia Saudita; entretanto Castillo et al. (2004, 2002) reportaron varias especies de Fusarium y sus micotoxinas asociadas en granos de frijol negro argentino.

Debido a la necesidad de más información sobre las especies de Fusarium presentes en el frijol común cultivado en Latinoamérica, incluída Costa Rica, resulta necesario identificar las especies que colonizan este grano, aspecto que contribuiría a determinar el riesgo de contaminación por micotoxinas en frijol y buscar alternativas futuras para su manejo. El objetivo del presente estudio fue identificar las especies de Fusarium que colonizan los granos de frijol negro en Costa Rica.

\section{MATERIALES Y MÉTODOS}

Aislamiento de los hongos. En 2017, 2018 y 2019 , se recolectaron durante la poscosecha 49 muestras de grano, de 500 g cada una, de frijol común ( $P$. vulgaris L.) de color negro, en diferentes regiones productoras de esta leguminosa en Costa Rica (Brunca, Central, Chorotega, Huetar Atlántico y Huetar Norte). Los granos se recolectaron en las fincas de personas productoras luego de la cosecha por lo que se encontraban almacenados por un período de no mas de 30 días antes de salir a la venta al mercado. El grano de frijol recolectado se almacenó en bolsas plásticas que contenían entre $0,5-1 \mathrm{~kg}$ de grano cada una y se colocaron en una cámara fría a $5^{\circ} \mathrm{C}\left(41^{\circ} \mathrm{F}\right)$ y $85 \%$ humedad relativa. Se almacenaron en esas condiciones por un período menor a 24 meses hasta el aislamiento fúngico.

Luego, el aislamiento de los hongos de cada muestra se realizó de la siguiente manera: 
se lavaron $50 \mathrm{~g}$ de frijol 3 veces con agua destilada esterilizada en autoclave $\left(121^{\circ} \mathrm{C}, 1,05 \mathrm{~kg} \cdot \mathrm{cm}^{-2}\right.$, 20 minutos). Después del último lavado, se colocaron 4 granos de frijol en placas Petri de $90 \mathrm{~mm}$ que contenían agar extracto de malta con $\mathrm{pH}$ de 5,5 $\left[20\right.$ g. $\mathrm{L}^{-1}$ de agar bacteriológico $\left(\right.$ Oxoid $^{\circledR}$ ) y 20 g.L.- ${ }^{-1}$ de extracto de malta $\left(\right.$ Difco $\left.^{\mathrm{TM}}\right)$ ]. Se realizaron 10 repeticiones por muestra, cada una compuesta por una placa de Petri con 4 granos de frijol. Los granos se incubaron a $25^{\circ} \mathrm{C}\left(77^{\circ} \mathrm{F}\right)$ en la oscuridad hasta que se observó el crecimiento de hongos (2-3 días de incubación). Se tomó una sección de aproximadamente $0,5 \mathrm{~cm}$ de micelio del margen de la colonia en activo crecimiento y se colocó en placas de Petri de $53 \mathrm{~mm}$ con agar extracto de malta. Se incubaron a $25^{\circ} \mathrm{C}$ por un período de 7 días en oscuridad. Luego de este tiempo, se observaron al microscopio secciones de micelio y esporas de cada cultivo y se eligieron los aislamientos que de acuerdo con Leslie y Summerell (2006), presentaban características distintivas de Fusarium, que incluían la forma y longitud de las esporas.

Para la preparación de los cultivos monospóricos, se tomaron esporas asexuales de los aislamientos seleccionados y se prepararon mediante el método de dilución seriada descrito por Leslie y Summerell (2006) con las siguientes modificaciones: se agregaron 500 $\mu l$ de agua del grifo autoclavada a cada placa que contenía micelio y la solución se mezcló mediante pipeteo para separar las esporas del micelio. La solución de esporas se colectó en un tubo de $2 \mathrm{ml}$ y se utilizó una alícuota para calcular la concentración de esporas con un hemocitómetro Fuchs-Rosenthal (Thomas Scientific, Horsham, PA, EE. UU.). La solución de esporas se diluyó para obtener 0,6 esporas. $\mu \mathrm{l}^{-1} \mathrm{y}$ se cultivó $50 \mu \mathrm{l}$ en placas de Petri de $90 \mathrm{~mm}$ que contenían Czapek Dox Agar (CDA, 50,01 g.L L $^{-1}$, pH 8,2, PhytoTechnology Laboratories ${ }^{\circledR}$ ). Los 50 $\mu \mathrm{l}$ se distribuyeron de forma homogénea sobre el medio de cultivo con ayuda de una espátula de Drigalski. Cada solución de esporas se cultivó de la misma manera por triplicado y se incubó a $25^{\circ} \mathrm{C}$ en oscuridad hasta que la germinación de cada espora fue visible a simple vista. Luego de 24 horas de incubación, 3 microcolonias de cada aislamiento se transfirieron por separado a un nuevo plato Petri con CDA y se incubaron en las mismas condiciones hasta que se produjo suficiente micelio para la extracción de ADN. Los aislamientos se numeraron consecutivamente de F1 a F79 para facilitar la identificación.

Identificación molecular de los aislamientos de Fusarium. El micelio proveniente de 79 cultivos monospóricos se separó cuidadosamente del medio y se liofilizó durante 3 días para eliminar totalmente el agua del material. El ADN se extrajo a partir de $20 \mathrm{mg}$ de micelio macerado según el método de extracción de ADN a gran escala de (Brandfass y Karlovsky 2008). La identificación molecular de los aislamientos se realizó mediante PCR en tiempo real y secuenciación con cebadores específicos diseñados para amplificar una región corta y variable de los genes $T E F-1 \alpha$ (factor de elongación de la traducción 1-alfa) y RPB2 (subunidad de la ARN polimerasa II) en Fusarium (Tabla 1).

Tabla 1. Secuencia de los cebadores utilizados para la identificación de los aislamientos de Fusarium obtenidos de granos de frijol común de color negro (Phaseolus vulgaris L.).

Costa Rica. 2017-2019.

\begin{tabular}{|c|c|c|c|}
\hline Nombre del cebador (gen) & Secuencia $\left(5^{\circ}-3^{\circ}\right)$ & Longitud del amplicón & Referencia \\
\hline RPB2-F2 (RPB2) & CAGAGGTATGGAAGTTGTTGA & \multirow{2}{*}{$177 \mathrm{bp}$} & Este estudio \\
\hline RPB2-R2 (RPB2) & ATnTCACGAACAAGnGAnAC & & Este estudio \\
\hline EF1_F2 $(T E F-1 \alpha)$ & TGTCAATCAGTCACTAACCA & \multirow{2}{*}{$257 \mathrm{bp}$} & Este estudio \\
\hline EF1_R2 $(T E F-1 \alpha)$ & TCATGTTCTTGATGAAATCAC & & Este estudio \\
\hline
\end{tabular}


La correcta amplificación de ambos cebadores en Fusarium se validó previamente con ADN de los siguientes controles positivos: $F$. avenaceum DSM62161, F. culmorum DSM62118, $F$. graminearum NRRL13383, $F$. langsethiae ESIER1400, F. oxysporum DSM62338, F. poae DSM62376, F. sporotrichioides DSM62423, $F$. tricinctum DSM23357 y $F$. verticillioides NRRL20956. El ADN de los controles positivos fue donado por el Prof. Dr. Petr Karlovsky (Molecular Phytopathology and Mycotoxin Research, Universidad de Göttingen, Alemania) y los hongos, a partir de los cuales se obtuvo el ADN fueron adquiridos en la DSMZ (German Collection of Microorganism and Cell Cultures $\mathrm{GmbH})$. La PCR en tiempo real se realizó en un termociclador Rotor-Gene Thermal Cycler RG-6000 (Corbett Research, Australia) y cada reacción de PCR se compuso de $12,3 \mu \mathrm{L}$ de mezcla maestra MeltDoctor (Applied Biosystems ${ }^{\circledR}$, Thermo Fisher Scientific, EE. UU.), 0,35 $\mu \mathrm{M}$ de cebadores directos e inversos (Tabla 1) y $2 \mu \mathrm{L}$ de ADN (17-167 ng $\left.\mu \mathrm{L}^{-1}\right)$ en un volumen final de $15 \mu \mathrm{L}$. Se utilizaron las siguientes condiciones de PCR para ambos cebadores: $95{ }^{\circ} \mathrm{C}$ durante $10 \mathrm{~min}, 40$ ciclos de: $95^{\circ} \mathrm{C}$ durante $15 \mathrm{~s} \mathrm{y} 60^{\circ} \mathrm{C}$ durante $1 \mathrm{~min}$. Tras el ciclo final de la PCR, se llevó a cabo el análisis de las curvas de temperatura de fusión que se inició a $95^{\circ} \mathrm{C}$ con una disminución de $0,3^{\circ} \mathrm{C}$ a $50^{\circ} \mathrm{C}$, esto para corroborar la amplificación y la especificidad de los amplicones. Los productos de PCR se enviaron a Macrogen (Corea del Sur) para su secuenciación. Se verificó la calidad de las secuencias y se realizó el alineamiento de las mismas con el empleo de la herramienta de alineación múltiple ClustalW (Thompson et al. 1994). Se eliminaron las secciones de secuencias que mostraban cromatogramas irregulares en los extremos 5 ' y 3 ' para evitar errores durante la identificación de las especies.
Las especies de Fusarium se identificaron mediante la herramienta Blast (Basic Local Alignment Search Tool) del Centro Nacional de Información Biotecnológica (NCBI) y se compararon con secuencias de la base de datos del GenBank (Clark et al. 2016). El análisis filogenético se realizó mediante el método de máxima verosimilitud con el programa MEGA-X (Análisis genético evolutivo molecular) versión 10.1 (Kumar et al. 2018). Los valores de bootstrap se generaron en cada nodo con 1000 réplicas.

\section{RESULTADOS}

Prevalencia de Fusarium en granos de frijol negro. De las 49 muestras de frijol negro, se obtuvieron 79 aislamientos de hongos que se codificaron consecutivamente de F1 a F79. De esos 79 aislamientos, 28 (35\%) fueron categorizados dentro del género Fusarium y se identificaron posteriormente a nivel molecular. Los demás hongos fueron descartados. La presencia de diferentes especies de Fusarium varió según el año de recolección de la muestra. En el 2017, el $50 \%$ de las muestras de frijol negro recolectadas estaban contaminadas con al menos una especie de Fusarium, mientras que en el 2018 y el 2019, el $43 \%$ y $76 \%$ de las muestras estuvieron contaminadas con Fusarium respectivamente.

Identificación molecular de los aislamientos de Fusarium. Del total de aislamientos de Fusarium, 82\% fueron identificados dentro del complejo de especies Fusarium incarnatumequiseti (FIESC) y clado VII según Watanabe et al. (2011) (Tabla 2 y Figura 1). Las especies identificadas dentro del FIESC fueron: $F$. hainanense, $F$. equiseti y $F$. Incarnatum; solo el $11 \%$ de los aislamientos (3 aislamientos) se identificaron como $F$. oxysporum y el $7 \%$ como $F$. verticillioides (2 aislamientos). 


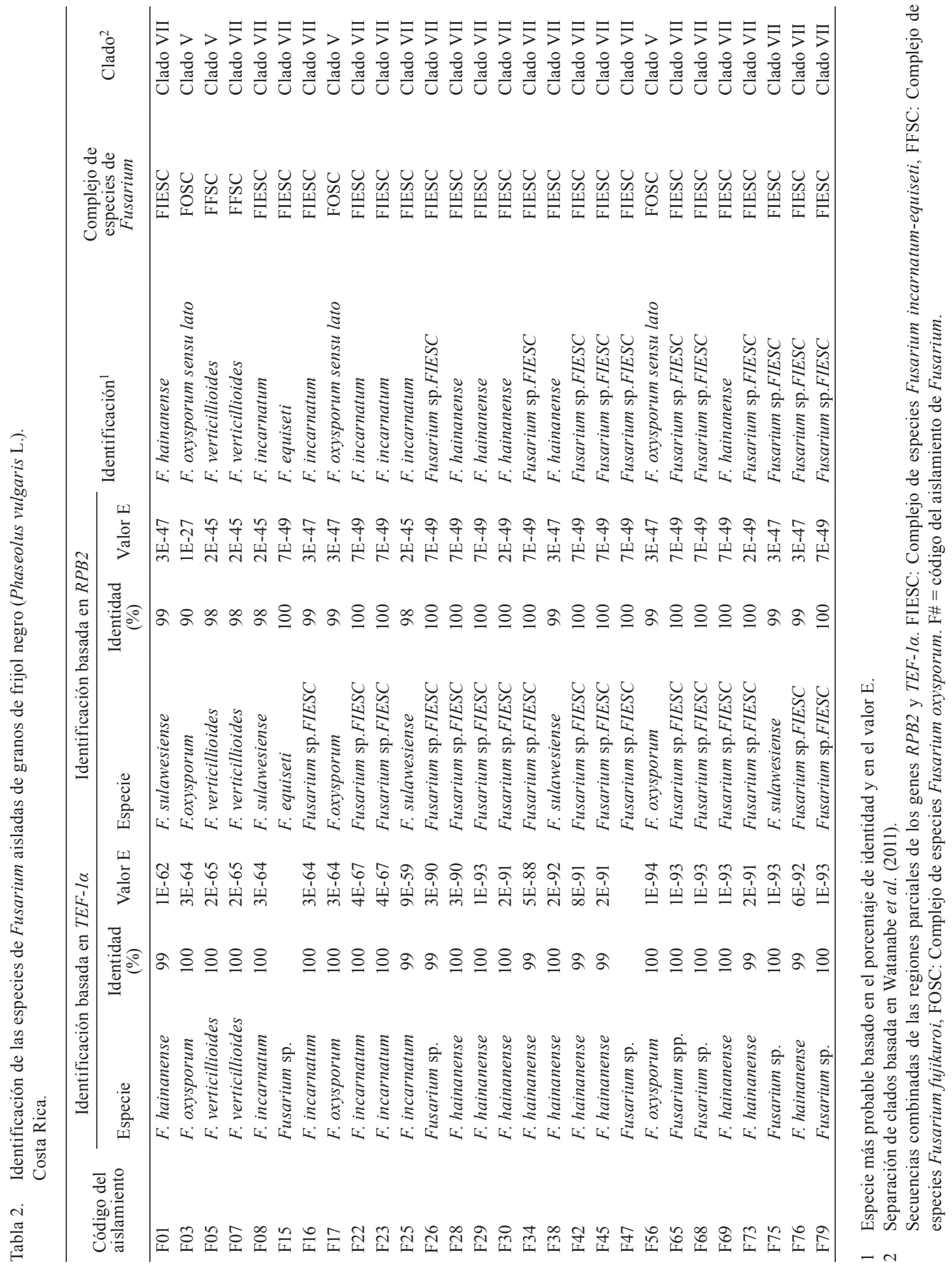




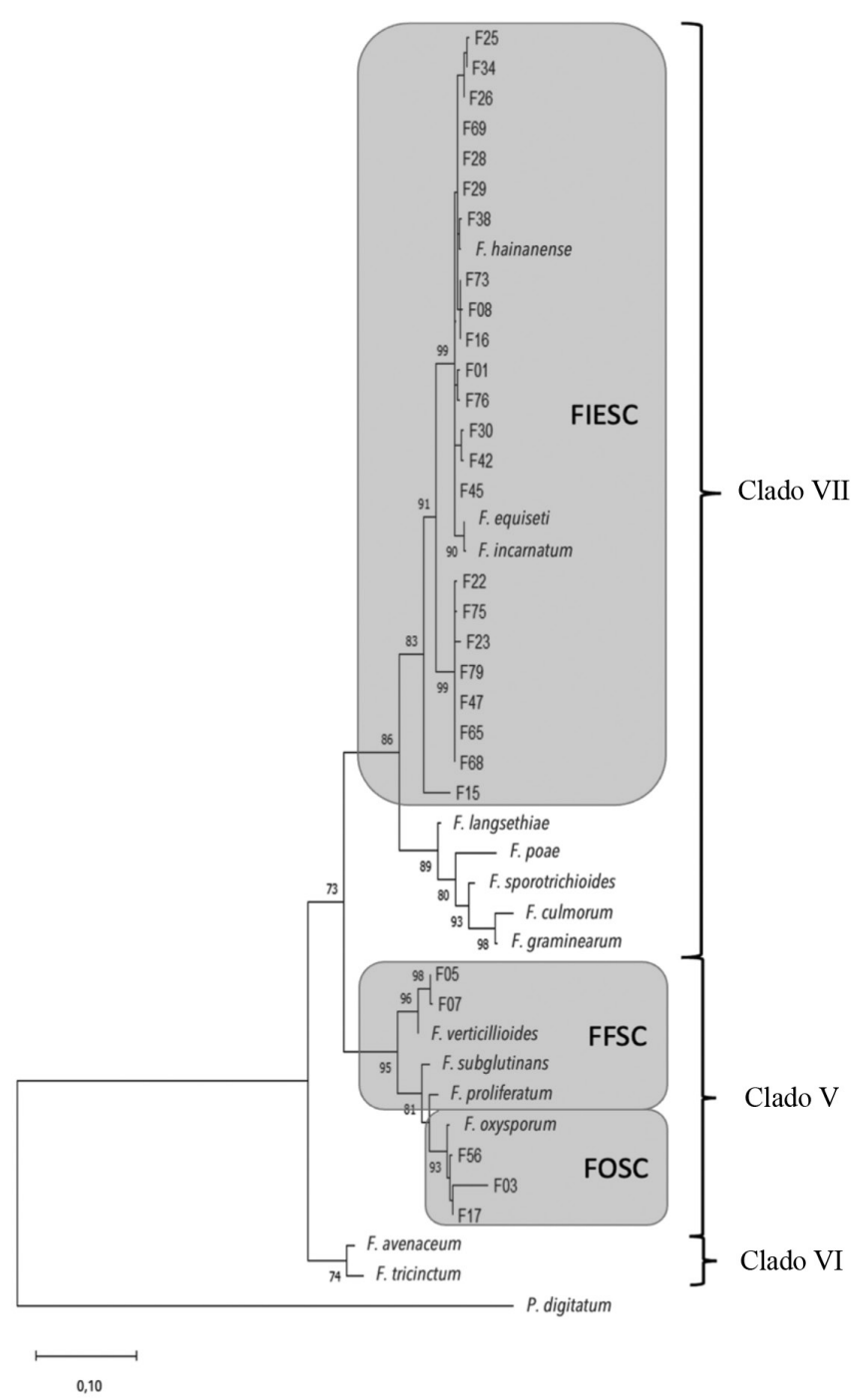

Figura 1. Árbol de máxima verosimilitud de los aislamientos de Fusarium obtenidos a partir de granos de frijol negro (Phaseolus vulgaris L.) en Costa Rica.

Las similitudes se infirieron a partir de las secuencias parciales combinadas de los genes RPB2 y TEF-1 $\alpha$. En cada nodo se muestran los valores de Bootstrap superiores al 70\% para 1000 réplicas.

FIESC $=$ complejo de especies Fusarium incarnatum-equiseti, FFSC $=$ complejo de especies Fusarium fujikuroi, $\mathrm{FOSC}=$ complejo de especies Fusarium oxysporum.

La separación de clados se basó en (Watanabe et al. 2011). F\# = código del aislamiento de Fusarium. Se utilizó Penicillium digitatum como grupo externo. 
Las especies más abundantes de Fusarium en el 2017 y 2019 incluyeron las pertenecientes al complejo de especies Fusarium incarnatumequiseti (FIESC), mientras que en el 2018 la mayoría de las muestras estaban contaminadas con $F$. incarnatum (Figura 2). Por otro lado, $F$. equisetti, solo estuvo presente en una muestra del 2018 y $F$. oxysporum estuvo presente en los 3 años evaluados, mientras que $F$. verticillioides solo en muestras del 2017 y 2018 (Figura 2).

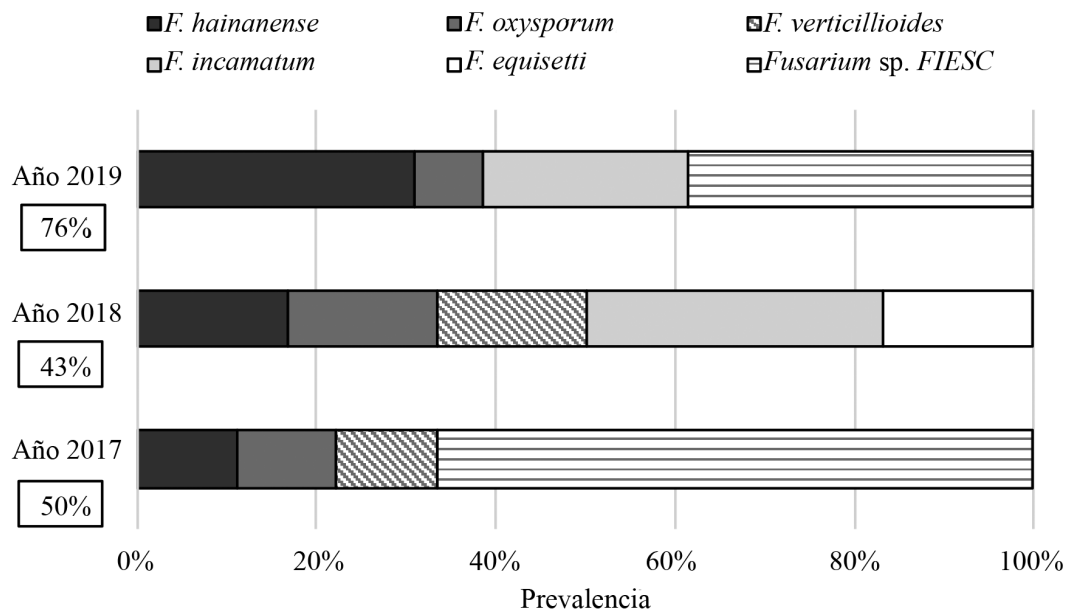

Figura 2. Prevalencia de especies de Fusarium aisladas de granos de frijol negro (Phaseolus vulgaris L.) recolectadas en 2017, 2018 y 2019 en Costa Rica. La identificación de las especies se realizó según las secuencias parciales combinadas de los genes RPB2 y TEF-1 $\alpha$ (ver Tabla 2).

Los porcentajes dentro de cada cuadrado se refieren a la prevalencia de Fusarium spp. en cada año.

La mayoría de las muestras fueron recolectadas en Pérez Zeledón, San José (Región Brunca) (Tabla 3), de las cuales se aisló el $71 \%$ de las especies de Fusarium. De los frijoles de esta Región se recuperaron 4 de las 6 especies identificadas de Fusarium en granos de frijol negro: $F$. hainanense, $F$. incarnatum, $F$. oxysporum y $F$. verticillioides, además, se aislaron especies que no pudieron ser identificadas pertenecientes al complejo de especies FIESC (Fusarium sp. FIESC) (Tabla 3). F. equisetti se aisló solo de una muestra proveniente de la Región Huetar Atlántica (Siquirres, Limón), mientras que $F$. incarnatum, $F$. oxysporum y $F$. verticillioides se encontraron distribuidos en muestras de frijol de diferentes regiones del país. 


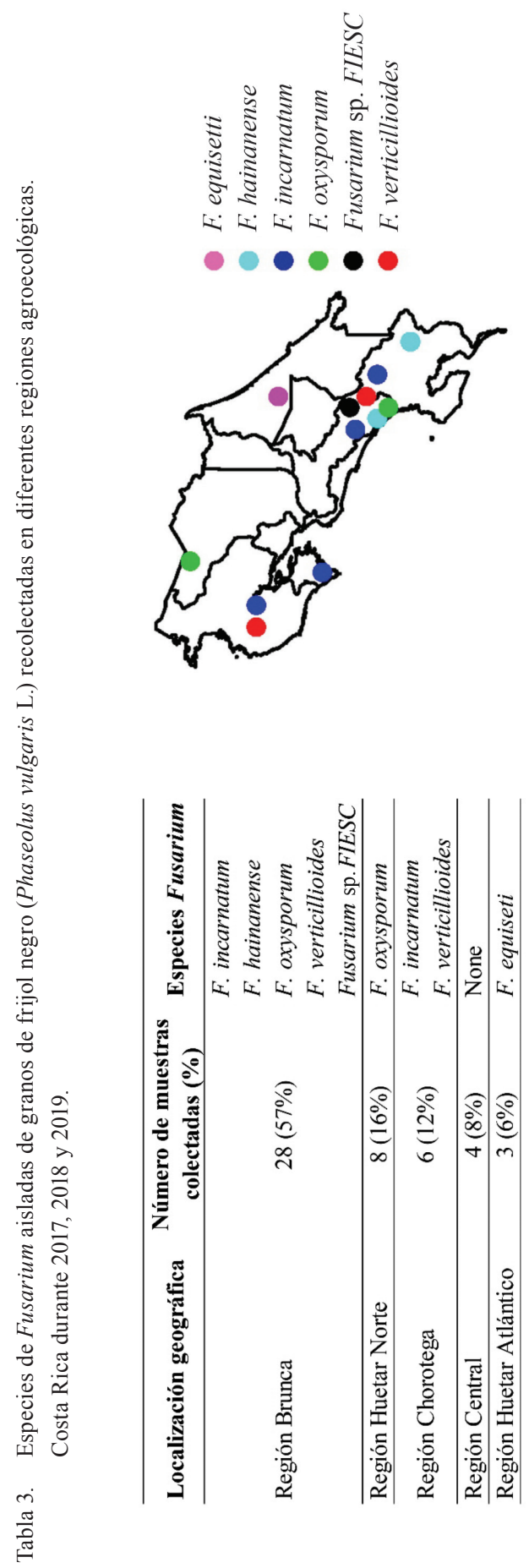

Agronomía Costarricense 45(2): 57-69. ISSN:0377-9424 / 2021 


\section{DISCUSIÓN}

Diversas especies de Fusarium han sido previamente aisladas de suelos, raíces, tallos y hojas del cultivo de frijol común (Phaseolus vulgaris L.). La mayoría de estas especies han sido identificadas como $F$. oxysporum o $F$. solani y están relacionadas a enfermedades como fusariosis o podredumbre radicular (Alves-Santos et al. 1999, Montiel-González et al. 2005, Macedo et al. 2017, Cruz et al. 2018). Existen pocos estudios que reporten la presencia de especies de Fusarium que colonicen granos de frijol común a nivel mundial. Hitokoto et al. (1981), reportaron la presencia de Fusarium en granos de frijol común colectados en mercados en la ciudad de Tokio, Japón, sin embargo, no identificaron las especies. Abdel-Hafez (1984) aisló F. oxysporum y $F$. solani a partir de granos de frijol común en Arabia Saudita; mientras que Tseng et al. (1995) identificaron 5 especies de Fusarium en granos de frijol canadiense con una incidencia de $18 \%$. En América Latina, (Castillo et al. 2002, 2004) reportaron la presencia de algunas especies de Fusarium en granos de frijol negro argentino, la mayoría identificadas como $F$. semitectum (prevalencia del 11\%) y F. graminearum (prevalencia del 4,8\%).

La mayoría $(82 \%)$ de las especies de Fusarium aisladas de granos de frijol negro en Costa Rica, en el presente estudio, pertenecían al complejo de especies FIESC ( $F$. hainanense, $F$. incarnatum, $F$. equiseti y otras), aunque también se identificaron $F$. oxysporum y $F$. verticillioides (Figura 1 y Tabla 2). Algunas de esas especies ya han sido reportadas en granos de frijol común en otros países (Abdel-Hafez 1984, Tseng et al. 1995, Castillo et al. 2002, 2004); no obstante, este es el primer reporte de $F$. hainanense y $F$. incarnatum identificados en granos de frijol común. Conocer las especies de Fusarium que colonizan los granos es relevante, ya que muchas pueden biosintetizar micotoxinas, metabolitos secundarios que tienen efectos adversos para la salud humana y animal (Wu et al. 2014, Ostry et al. 2017). Varios miembros del complejo de especies FIESC son saprófitos y oportunistas; además, algunos de ellos son conocidos por su capacidad para producir micotoxinas como beauvericina (Logrieco et al. 1998), diacetoxiscirpenol, fusarenona X, nivalenol (Villani et al. 2016), zearalenona y deoxinivalenol (Avila et al. 2019).

Las otras 2 especies de Fusarium no pertenecientes al FIESC que se identificaron en las muestras de frijol común negro en Costa Rica, $F$. oxysporum y $F$. verticillioides, son importantes patógenos que colonizan las plantas, pero difieren en su potencial micotoxigénico. Por ejemplo, F. oxysporum no es un hongo conocido por su capacidad micotoxigénica, aunque se ha reportado que esta especie produce algunas micotoxinas dentro del grupo de los tricotecenos (Lee et al. 1986, Mirocha et al. 1989, Richard et al. 2007, Li et al. 2016). Asimismo F. verticillioides es una de las especies de Fusarium más relevantes por su capacidad para producir micotoxinas. Esta especie produce fumonisinas que son reconocidas por su potencial cancerígeno en humanos y animales (Norred 1993, Covarelli et al. 2012, Ostry et al. 2017).

Trabajos de investigación previos reportaron prevalencia de Fusarium menor al 19\% en granos de frijol común (Hitokoto et al. 1981, Abdel-Hafez 1984, Tseng et al. 1995, Castillo et al. 2002, 2004), lo cual contrasta con estos resultados. En el presente trabajo se encontró una prevalencia de Fusarium de más del $43 \%$ en las muestras de granos de frijol negro colectadas en diferentes años (Figura 2). Estas muestras fueron recolectadas después de la cosecha en condiciones de almacenamiento en campo similares a las de Castillo et al. (2002, 2004); sin embargo, esas personas autoras reportaron alrededor de un $19 \%$ de prevalencia de Fusarium en granos de frijol negro argentino. Las condiciones climáticas pudieran explicar estas diferencias, ya que el frijol argentino proviene de la provincia de Salta, donde la temperatura y precipitación promedio anual son $20^{\circ} \mathrm{C}\left(68^{\circ} \mathrm{F}\right)$ y $500 \mathrm{~mm}$, respectivamente (Portal informativo de Salta 2020). Mientras que en Pérez Zeledón (Región Brunca). En Costa Rica, donde se recolectaron la mayoría 
de las muestras en este estudio se presentó una temperatura promedio anual de $23^{\circ} \mathrm{C}\left(74^{\circ} \mathrm{F}\right)$, pero la precipitación promedio anual es mucho más alta, 2944 mm (Climate-data.org 2020). Los patrones de alta precipitación se han relacionado previamente con la infestación por Fusarium en cereales y granos (Gamanya y Sibanda 2001, Bernhoft et al. 2012, Tsehaye et al. 2017) por lo que se esperarían valores elevados de prevalencia de este hongo en zonas de alta precipitación como Pérez Zeledón.

El presente estudio mostró por primera vez la diversidad de especies de Fusarium en granos de frijol negro en Costa Rica, donde la ubicación geográfica es considerada región agroecológica así como el año de recolección de la muestra. La prevalencia de especies de Fusarium en los granos de frijol negro fue alta, pues llegó a un $76 \%$ en muestras recolectadas en el 2019. La mayoría de los aislamientos de Fusarium pertenecen al complejo de especies FIESC que tienen varios integrantes con potencial micotoxigénico. Además, se identificaron 2 importantes especies fitopatógenas de Fusarium: $F$. oxysporum y $F$. verticillioides; esta última conocida por su potencial toxigénico, ya que produce fumonisina, una de las micotoxinas más relevantes desde el punto de vista de salud humana. Debido a que la capacidad de un hongo como Fusarium puede causar enfermedades en una planta o producir micotoxinas depende del sustrato y de las condiciones ambientales, se deberían realizar investigaciones complementarias para determinar el potencial que tienen, las especies identificadas en el presente estudio de causar enfermedades o producir micotoxinas en el frijol negro en Costa Rica.

\section{AGRADECIMIENTOS}

Las autoras agradecen a la Vicerrectoría de Investigación de la Universidad de Costa Rica por el apoyo financiero otorgado para el desarrollo de esta investigación en el marco del proyecto VI-734-B9-038.

\section{LITERATURA CITADA}

Abdel-Hafez, SII. 1984. Mycoflora of bean, broad bean, lentil, lupine and pea seeds in Saudi Arabia. Mycopathologia 88(1):45-49.

Alves-Santos, FM; Benito, EP; Eslava, AP; Díaz-Mínguez, J. 1999. Genetic diversity of Fusarium oxysporum strains from common bean fields in Spain. Applied and Environmental Microbiology 65(8):3335-3340.

Antonissen, G; Martel, A; Pasmans, F; Ducatelle, $\mathrm{R}$; Verbrugghe, E; Vandenbroucke, V; Li, S; Haesebrouck, F; Van Immerseel, F; Croubels, S. 2014. The impact of Fusarium mycotoxins on human and animal host susceptibility to infectious diseases. Toxins 6(2):430-452.

Avila, CF; Moreira, GM; Nicolli, CP; Gomes, LB; Abreu, LM; Pfenning, LH; Haidukowski, M; Moretti, A; Logrieco, A; Del Ponte, EM. 2019. Fusarium incarnatum-equiseti species complex associated with Brazilian rice: Phylogeny, morphology and toxigenic potential. International Journal of Food Microbiology 306:108267.

Bernhoft, A; Torp, M; Clasen, P-E; Løes, A-K; Kristoffersen, AB. 2012. Influence of agronomic and climatic factors on Fusarium infestation and mycotoxin contamination of cereals in Norway. Food Additives \& Contaminants: Part A 29(7):1129-1140.

Blair, MW; González, LF; Kimani, PM; Butare, L. 2010. Genetic diversity, inter-gene pool introgression and nutritional quality of common beans (Phaseolus vulgaris L.) from Central Africa. Theoretical and Applied Genetics 121(2):237-248.

Brandfass, C; Karlovsky, P. 2008. Upscaled CTAB-Based DNA Extraction and Real-Time PCR Assays for Fusarium culmorum and $F$. graminearum DNA in Plant Material with Reduced Sampling Error. International Journal of Molecular Sciences 9(11):2306-2321.

Broughton, WJ; Hernández, G; Blair, M; Beebe, S; Gepts, P; Vanderleyden, J. 2003. Beans (Phaseolus spp.) model food legumes. Plant and Soil 252(1):55-128.

Castillo, M; Samar, M; Moltó, G; Resnik, S; Pacin, A 2002. Trichothecenes and zearalenone production by fusarium species isolated from Argentinean black beans. Mycotoxin Research 18(1):31-36.

Castillo, MD; González, HHL; Martínez, EJ; Pacin, AM; Resnik, SL. 2004. Mycoflora and potential for mycotoxin production of freshly harvested black bean from the Argentinean main production area. Mycopathologia 158(1):107-112.

Cinar, A; Onbaşı, E. 2019. Mycotoxins: The Hidden Danger in Foods. London, UK., IntechOpen. p. 21.

Clark, K; Karsch-Mizrachi, I; Lipman, DJ; Ostell, J; Sayers, EW. 2016. GenBank. Nucleic Acids Research 44(D1):D67-D72. 
Climate-data.org. 2020. El Clima (en línea). San José, Costa Rica, Municipalidad de Pérez Zeledón. Consultado 6 ago. 2020. Disponible en https://www. perezzeledon.go.cr/index.php/turismo/informacionturistica/el-clima.html

Covarelli, L; Stifano, S; Beccari, G; Raggi, L; Lattanzio, VMT; Albertini, E. 2012. Characterization of Fusarium verticillioides strains isolated from maize in Italy: Fumonisin production, pathogenicity and genetic variability. Food Microbiology 31(1):17-24.

Cruz, AF; Silva, LF; Sousa, TV; Nicoli, A; de Paula Junior, TJ; Caixeta, ET; Zambolim, L. 2018. Molecular diversity in Fusarium oxysporum isolates from common bean fields in Brazil. European Journal of Plant Pathology 152(2):343-354.

Eskola, M; Kos, G; Elliott, CT; Hajšlová, J; Mayar, S; Krska, R. 2019. Worldwide contamination of food-crops with mycotoxins: Validity of the widely cited 'FAO estimate' of $25 \%$. Critical Reviews in Food Science and Nutrition 0(0):1-17.

FAO. 2018. New food balances. Roma, Italia (en línea). Consultado 22 feb. 2021. Disponible en http://www. fao.org/faostat/en/\#data/FBS

FAO. 2019. The global economy of pulses. In Vikas, R; Kalamvrezos Navarro, D. Rome, Italia, Food and Agriculture Organization of the United Nations. $174 \mathrm{p}$.

Gamanya, R; Sibanda, L. 2001. Survey of Fusarium moniliforme ( $F$. verticillioides) and production of fumonisin B1 in cereal grains and oilseeds in Zimbabwe. International Journal of Food Microbiology 71(2):145-149.

Gepts, P; Aragão, FJL; Barros, E de; Blair, MW; Brondani, R; Broughton, W; Galasso, I; Hernández, G; Kami, J; Lariguet, P; McClean, P; Melotto, M; Miklas, P; Pauls, P; Pedrosa-Harand, A; Porch, T; Sánchez, F; Sparvoli, F; Yu, K. 2008. Genomics of Phaseolus beans, a major source of dietary protein and micronutrients in the tropics. In Moore, PH; Ming, R (eds.). Plant Genetics and Genomics: Crops and Models. New York, NY, Springer p. 113-143.

Hitokoto, H; Morozumi, S; Wauke, T; Sakai, S; Kurata, H. 1981. Fungal contamination and mycotoxinproducing potential of dried beans. Mycopathologia 73(1):33-38.

Jiménez-García, S; García-Mier, L; García-Trejo, JF; Ramírez-Gómez, XS; Guevara-González, RG; Feregrino-Pérez, AA. 2018. Fusarium mycotoxins and metabolites that modulate their production. London, UK., IntechOpen, vol. 3. p. 695.

Kumar, S; Stecher, G; Li, M; Knyaz, C; Tamura, K. 2018. MEGA X: Molecular evolutionary genetics analysis across computing platforms. Molecular Biology and Evolution 35(6):1547-1549.

Lee, US; Jang, HS; Tanaka, T; Toyasaki, N; Sugiura, Y; Oh, YJ; Cho, CM; Ueno, Y. 1986. Mycological survey of Korean cereals and production of mycotoxins by Fusarium isolates. Applied and Environmental Microbiology 52(6):1258-1260.

Leslie, JF; Summerell, BA. 2006. The Fusarium Laboratory Manual. 5 ed. Iowa, USA, John Wiley \& Sons. 402 p.

Li, ZF; He, CL; Wang, Y; Li, MJ; Dai, YJ; Wang, T; Lin, W. 2016. Enhancement of trichothecene mycotoxins of Fusarium oxysporum by ferulic acid aggravates oxidative damage in Rehmannia glutinosa Libosch. Scientific Reports 6(1):33962.

Logrieco, A; Moretti, A; Castella, G; Kostecki, M; Golinski, P; Ritieni, A; Chelkowski, J. 1998. Beauvericin production by Fusarium species. Applied and Environmental Microbiology 64(8):3084-3088.

Macedo, R; Sales, LP; Yoshida, F; Silva-Abud, LL; Junior, ML. 2017. Potential worldwide distribution of Fusarium dry root rot in common beans based on the optimal environment for disease occurrence. PLOS ONE 12(11):e0187770.

Marin, S; Ramos, AJ; Cano-Sancho, G; Sanchis, V. 2013. Mycotoxins: Occurrence, toxicology, and exposure assessment. Food and Chemical Toxicology 60:218-237.

Mensack, MM; Fitzgerald, VK; Ryan, EP; Lewis, MR; Thompson, HJ; Brick, MA. 2010. Evaluation of diversity among common beans (Phaseolus vulgaris L.) from two centers of domestication using «omics» technologies. BMC Genomics 11(1):686.

Mirocha, CJ; Abbas, HK; Kommedahl, T; Jarvis, BB. 1989. Mycotoxin production by Fusarium oxysporum and Fusarium sporotrichioides isolated from Baccharis spp. from Brazil. Applied and Environmental Microbiology 55(1):254-255.

Montiel-González, L; González-Flores, F; SánchezGarcía, BM; Guzmán-Rivera, S; Gámez-Vázquez, FP; Acosta-Gallegos, JA; Rodríguez-Guerra, R; Simpson-Williamson, J; Cabral-Enciso, M; Mendoza-Elos, M. 2005. Fusarium species on bean (Phaseolus vulgaris L.) roots causing rots, in fives states of Central Mexico. Revista Mexicana de Fitopatología 23(1):1-10.

Munkvold, GP. 2017. Fusarium Species and Their Associated Mycotoxins (en línea). In Moretti, A; Susca, A (eds.). Methods in Molecular Biology. New York, NY, Springer. p. 51-106. DOI: https://doi. org/10.1007/978-1-4939-6707-0_4.

Norred, WP. 1993. Fumonisins-mycotoxins produced by Fusarium moniliforme. Journal of Toxicology and Environmental Health 38(3):309-328.

Omotayo, OP; Omotayo, AO; Mwanza, M; Babalola, OO. 2019. Prevalence of Mycotoxins and Their Consequences on Human Health. Toxicological Research 35(1):1-7.

Oomah, BD; Cardador-Martínez, A; Loarca-Piña, G. 2005. Phenolics and antioxidative activities in common 
beans (Phaseolus vulgaris L). Journal of the Science of Food and Agriculture 85(6):935-942.

Ostry, V; Malir, F; Toman, J; Grosse, Y. 2017. Mycotoxins as human carcinogens-the IARC Monographs classification. Mycotoxin Research 33(1):65-73.

Perrone, G; Ferrara, M; Medina, A; Pascale, M; Magan, N. 2020. Toxigenic Fungi and Mycotoxins in a Climate Change Scenario: Ecology, Genomics, Distribution, Prediction and Prevention of the Risk. Microorganisms 8(10):1496.

Portal informativo de Salta. 2020. Clima de la provincia de Salta (en línea). Salta, Argentina, Ministerio de Defensa, Servicio Meteorológico Nacional. Consultado 6 ago. 2020. Disponible en http://www. portaldesalta.gov.ar/clima.htm

Richard, E; Heutte, N; Sage, L; Pottier, D; Bouchart, V; Lebailly, P; Garon, D. 2007. Toxigenic fungi and mycotoxins in mature corn silage. Food and Chemical Toxicology 45(12):2420-2425.

SEPSA (Secretaría Ejecutiva de Planificación Sectorial Agropecuaria). 2018. Extensión sembrada y cosechada en hectáreas y producción en toneladas métricas, según cultivo. San José, Costa Rica, Ministerio de Agricultura y Ganadería de Costa Rica. 1 p.

SEPSA (Secretaría Ejecutiva de Planificación Sectorial Agropecuaria). 2019. Área sembrada y producción de frijol según región y subregión, por período agrícola 2016/17-2018/19. San José, Costa Rica, Ministerio de Agricultura y Ganadería de Costa Rica. 1 p.

Singleton, P; Sainsbury, D. 2006. Dictionary of microbiology and molecular biology. 3 ed rev. Chichester, West Sussex ; Hoboken, NJ, Wiley. 895 p.
Summerell, BA; Laurence, MH; Liew, ECY; Leslie, JF. 2010. Biogeography and phylogeography of Fusarium: a review. Fungal Diversity 44(1):3-13.

Thompson, JD; Higgins, DG; Gibson, TJ. 1994. CLUSTAL W: improving the sensitivity of progressive multiple sequence alignment through sequence weighting, position-specific gap penalties and weight matrix choice. Nucleic Acids Research 22(22): 4673-4680.

Tsehaye, H; Brurberg, MB; Sundheim, L; Assefa, D; Tronsmo, A; Tronsmo, AM. 2017. Natural occurrence of Fusarium species and fumonisin on maize grains in Ethiopia. European Journal of Plant Pathology 147(1):141-155.

Tseng, TC; Tu, JC; Tzean, SS. 1995. Mycoflora and mycotoxins in dry bean (Phaseolus vulgaris) produced in Taiwan and in Ontario, Canada. Botanical Bulletin Academia Sinica Taipei 36:229-234.

Villani, A; Moretti, A; De Saeger, S; Han, Z; Di Mavungu, JD; Soares, CMG; Proctor, RH; Venâncio, A; Lima, N; Stea, G; Paciolla, C; Logrieco, AF; Susca, A 2016. A polyphasic approach for characterization of a collection of cereal isolates of the Fusarium incarnatum-equiseti species complex. International Journal of Food Microbiology 234:24-35.

Watanabe, M; Yonezawa, T; Lee, K; Kumagai, S; SugitaKonishi, Y; Goto, K; Hara-Kudo, Y. 2011. Molecular phylogeny of the higher and lower taxonomy of the Fusariumgenus and differences in the evolutionary histories of multiple genes. BMC Evolutionary Biology 11(1):322.

Wu, F; Groopman, JD; Pestka, JJ. 2014. Public health impacts of foodborne mycotoxins. Annual Review of Food Science and Technology 5(1):351-372.

Todos los derechos reservados. Universidad de Costa Rica. Este artículo se encuentra licenciado con Creative Commons Reconocimiento-NoComercial-SinObraDerivada 3.0 Costa Rica. Para mayor información escribir a rac.cia@ucr.ac.cr 
